\title{
As Influências das Transformações Midiáticas e Tecnológicas no Tempo e Espaço de Lazer dos Alunos na Escola Municipal São Luiz
}

The influences of technological and media transformations on time and space used for leisure by students at the São Luiz Municipal School

Andreza Santana De Abreu Silva, Especialização em Educação Física Escolar, Universidade Federal do Paraná, andrezaabreusilva@gmail.com.

\section{Resumo}

Entender o universo das tecnologias da informação e comunicação e influências nas escolhas das crianças ao brincar. Principalmente na sociedade contemporânea conectada aos meios digitais. Torna-se interessante compreender como ocorrem as relações nesse ambiente sociocultural de práticas antigas aliadas às novas modalidades de aprendizagem nunca antes imaginadas por gerações posteriores.

Palavras Chave: educação, lazer, tecnologia

\section{Abstract}

The objective of this paper is to understand the universe of information and communication technologies and their influences on the choices children make when they play, especially in a contemporary society that is connected to digital media. It is interesting to understand how relationships occur in this socio-cultural environment in which older practices are combined with new forms of learning in ways that are unimaginable to later generations.

Keywords: education, leisure, technology. 


\section{Introdução}

A presença de traços do imaginário midiático na cultura de movimento das crianças em vivências lúdicas no ambiente escolar se constitui nas brincadeiras das crianças, e mais, especificamente, as suas diferentes formas de movimentar-se enquanto brincam livremente. Atualmente ocorrem grandes mudanças relacionadas à presença das mídias com destaque as eletrônicas no universo das brincadeiras e do lazer no cotidiano infantil.

O consumo infantil tem se tornado um tema cada vez mais recorrente na atualidade, potencializando um debate que se dá em diversas direções. É uma temática que atua nas interações da vida cotidiano (Brasília, 2009 p. 60).

Na sociedade contemporânea, pode-se perceber a reformulação do conceito de infância. Novamente, moldada pelos fatores culturais, que se baseiam também no avanço constante da tecnologia, nota-se que as crianças se relacionam com o meio em que vivem de modo particular. Pereira (2002) o conceito moderno de infância se molda no próprio surgimento do capitalismo, em que ser criança ainda se traduz na dependência do adulto, pelo processo de aprendizagem da escrita e leitura, sendo este, entre outros fatores, o que diferencia o estágio infantil do adulto. A autora ainda argumenta que essa relação da dependência da criança em torno do adulto pode ser relativizada, ao se considerar que a modelagem da infância tem sido pautada pelo domínio das técnicas de comunicação e da tecnologia. Percebe-se que as crianças dos dias atuais estão inseridas em um contexto de tecnologia e lidam com isso bem melhor que os adultos. Estes, por vez encaram as transformações tecnológicas como um problema, implicando uma readequação aos padrões sociais.

É possível entender que de fato as crianças lidam com as tecnologias de maneira específica, ou seja, a criança enquanto ser social atuante convive com modelos e moldes culturais apresentados a elas. (Brasília, 2009. p. 64). Quando a esse universo eram antigamente apresentadas apenas formas de lazer e brincadeiras combinadas de acordo com as tecnologias da sociedade, podemos analisar que as mesmas sempre lidaram e lidam muito bem de acordo com o que Ihes é oferecido.

Pois devemos considerar que é nas imagens e símbolos da cultura na qual está inserida que a criança busca elementos para criar seus roteiros de brincadeira e representações. Fernandes (2004).

Uma brincadeira pode reunir construções morais próprias dos períodos históricos em que foi criada, desde que esta moral preencha ainda determinadas funções sociais Ao estudarmos a presença das mídias, no universo lúdico infantil, devemos considerar que a escola faz parte desse universo infantil, pois é dentro dela que se dá a maioria dessas experiências, ou a troca delas. A escola então se torna um lugar de descobertas e ampliação das experiências individuais, culturais, sociais e educativas, ao inserirmos a criança em ambientes distintos dos da família. 
A pesquisa procura investigar como se dá o lazer dessas crianças fora da escola, e se há ou não grande influência da mídia e das novas gerações tecnológicas. Procura-se averiguar a que ponto as crianças relacionam lazer com atividades práticas de movimentos, se entendem a importância da atividade física, mesmo que seja de recreação como indicador de melhoria da qualidade de vida.

Quando analisamos a brincadeira dentro da escola como momentos únicos de lazer para a criança, temos então um grande leque de possibilidades de analisar como se processam esses momentos dentro da escola, seja numa brincadeira de pega-pega, numa leitura de um livro, ou até mesmo dentro das aulas de Educação Física. A reflexão sobre a relação entre as crianças às mídias e as tecnologias do mundo contemporâneo enfatiza a importância das mediações e do contexto cultural nos processos de recepção. Os movimentos geralmente fazem referência a personagens e cenários, criando situações e roteiros para brincar em seus momentos mais solitários ou em grupos, geralmente surgem a partir de histórias e programas de televisão, ou joguinhos eletrônicos encontrados nos tablets, celulares e computadores, dessa forma as crianças refletem e questionam, à sua maneira, o mundo que as cerca. Portanto o lazer dessas crianças atualmente está centrado nas projeções que as mídias e as tecnologias eletrônicas direcionam?

\section{Metodologia}

As tecnologias de informação e comunicação estão presentes no cotidiano de todos, com mais ou menos intensidade, e não pode ser ignorada. Vivemos em um mundo em que os meios de comunicação estão se tornando indispensáveis. É de grande importância que se tenha uma educação para o lazer, assim como se faz necessária uma educação para a mídia. É nesse sentido que se faz necessário entender o papel do professor dentro da sua formação, ao lidar com esse novo tema. O professor deve ter subsídios para realizar intervenções pedagógicas, tanto no nível da educação básica, quanto em nível superior na formação de futuros professores; para que se formem aptos a realizar mediações, discussões e leituras de qualidade acerca dos mais variados momentos de lazer que cada sujeito queira produzir durante sua vida, contribuindo para que possam vir a ter vivências de qualidade em seus momentos de lazer.

As práticas corporais desenvolvidas pelos sujeitos no tempo e espaço de lazer constituem um objeto a ser tratado com seriedade, principalmente pela escola, pois é durante estas vivências que os alunos adquirem a maior parte dos hábitos que levarão por toda a vida. Uma vez que a escola é o local em que se vivencia o lúdico e o desenvolvimento de práticas diversificadas, que podem gerar nos alunos uma vida com melhor qualidade.

Diante dessa problemática houve o interesse em desenvolver uma pesquisa para compreender a situação da Escola Municipal São Luiz acerca das estratégias didáticas metodológicas para tratar do tema lazer no âmbito dos recursos das 
tecnologias de informação e comunicação por ela utilizadas, diante disso analisar quais os limites e possibilidades de tematização do lazer para todo o universo dessa escola.

Para isso foi utilizado um questionário com alunos do turno da tarde, na Escola Municipal São Luiz, com turmas do terceiro, quarto e quinto ano. Com idade de 8 a 10 anos. Uma vez que características socioeconômicas dos alunos do período da tarde são diferentes dos alunos do período da manhã. Os alunos do período da manhã, a maioria vem de bairros afastados da região e durante o período da tarde permanecem no Lar dos Meninos São Luiz, mantido pela igreja, um projeto sem ligação alguma com a Prefeitura Municipal de Curitiba. Os alunos do período da tarde, por sua vez, são crianças da região do bairro Água Verde.

$\mathrm{Na}$ pesquisa foi colocado perguntas para analisar o tipo de moradia de cada aluno, suas escolhas no brincar, se possuem espaços para atividades externas, e se suas preferências no brincar se relacionam com personagens e jogos eletrônicos que fazem parte do universo infantil. Por fim foi solicitado que os alunos escrevessem o que fazem nos momentos livres.

Os resultados desses dados vieram por aplicação de um questionário com quatro turmas: dois terceiros anos, um quarto ano e um quinto ano. Crianças com idade de 8 a 10 anos. 0 questionário foi realizado no momento da aula de Educação Física. A professora leu com os alunos todas as questões na qual eles iam marcando suas opções. Em algumas questões eles poderiam marcar mais de uma opção.

Através desses dados pretendeu-se: Analisar os limites e possibilidades de tematização do lazer nas aulas de Educação Física a partir do uso das tecnologias de informação e comunicação e investigar as relações entre mídia, tecnologias e lazer, bem como suas implicações no cotidiano da escola. O resultado obtido foi adicionado nos gráficos abaixo. As análises foram realizadas a partir das respostas dos alunos e confrontadas com os objetivos dessa pesquisa:

Gráfico 1: Você gosta de esportes?

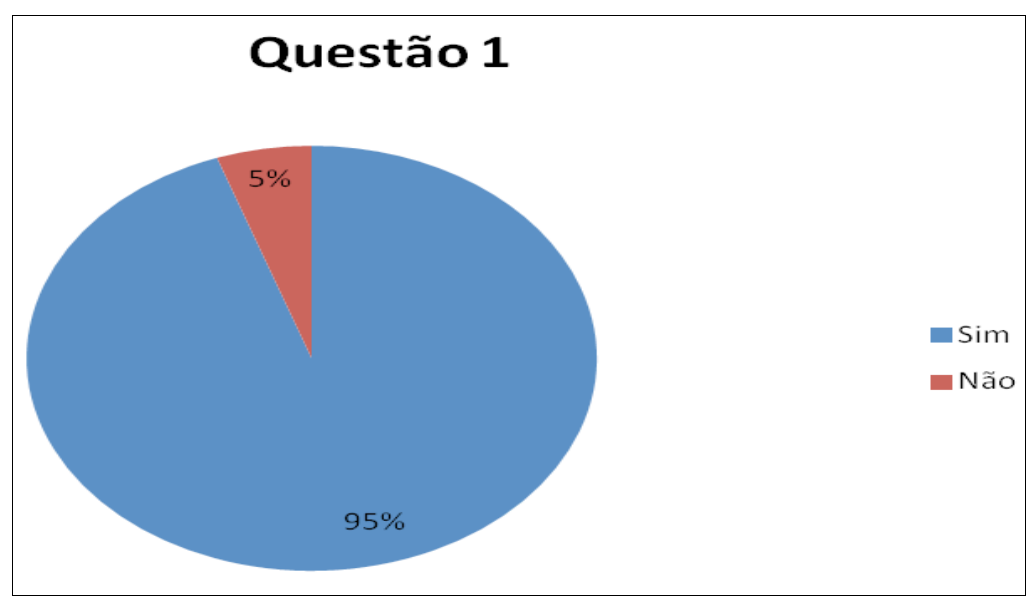




\section{SILID IV

Nesse gráfico notamos que os a maioria dos alunos gosta de esporte, isso não significa que pratiquem, mas que se identificam com a prática de esportes.

\section{Gráfico 2}

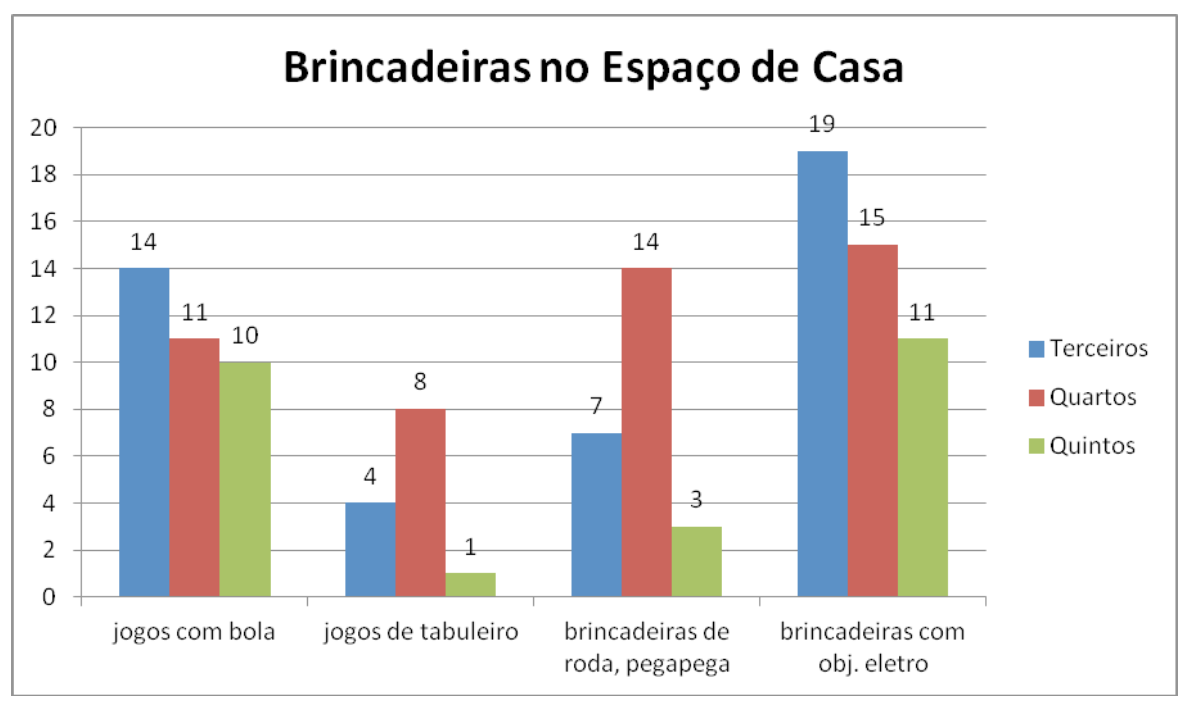

No gráfico acima percebemos que a oscilação entre as preferências no brincar mudam conforme a faixa etária. Por isso nos terceiros anos a incidência é maior em brincar com jogos eletrônicos, mas notamos que as brincadeiras tradicionais não ficam tão atrás assim. Esse cenário se deve ao fato de a maioria dessas crianças residirem conforme a pesquisa identificou que as grandes partes dos alunos que responderam ao questionário residem em prédios, onde grande parte não consegue utilizar seus espaços de lazer cotidianamente.

\section{Gráfico 3}

\section{Tipos de Games}

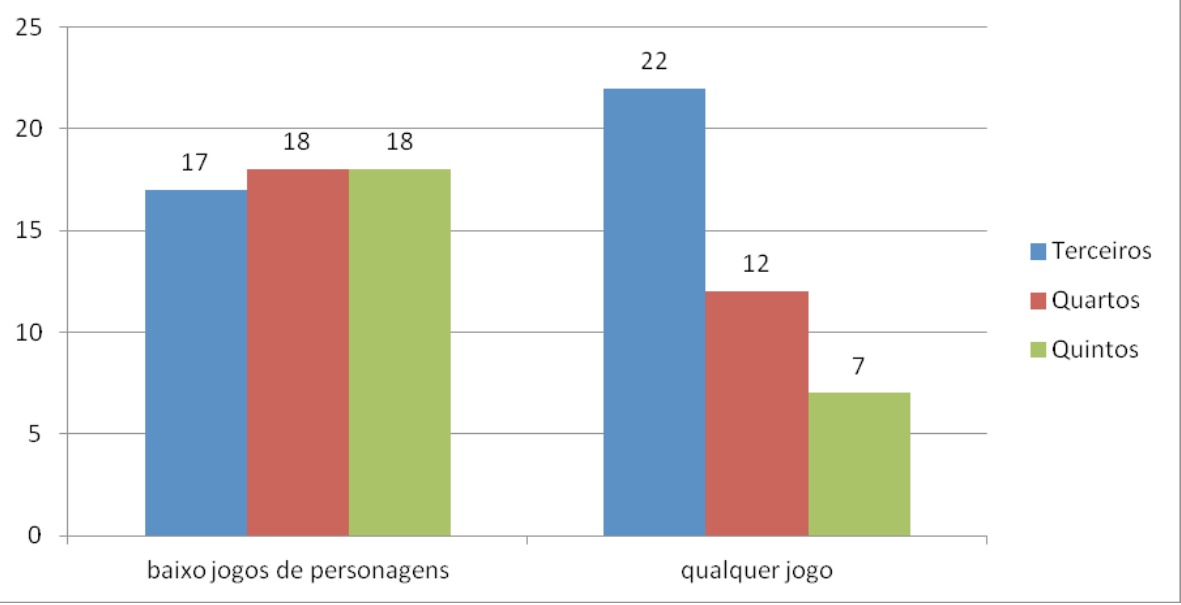


Na pesquisa surgiu à questão com relação aos jogos eletrônicos, e sua relação com preferências de jogos de acordo com personagens da mídia, uma vez que na própria pesquisa foi constatado que a maioria dos alunos permanecem dentro de casa no período contrário ao escolar e acessando a TV ou aos jogos eletrônicos.

\section{Gráfico4}

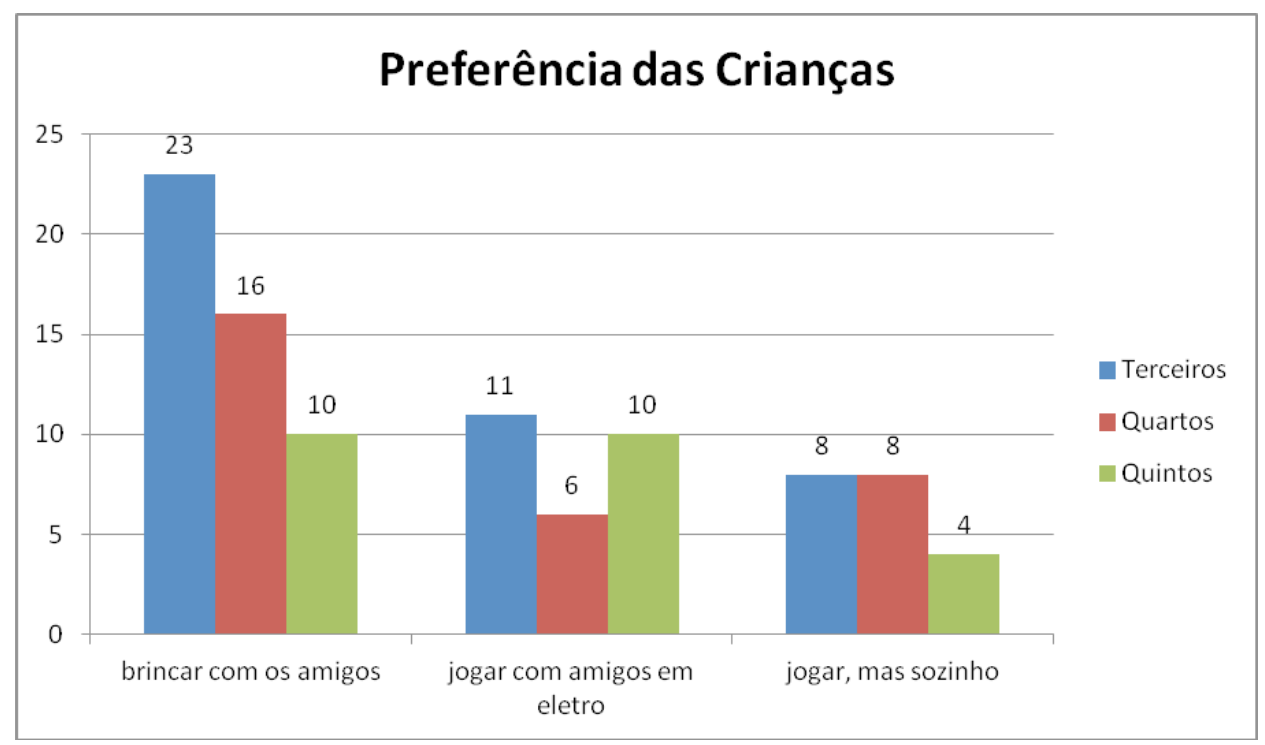

Esse gráfico nos traz respostas sobre questões colocadas no inicio dessa pesquisa, ou seja, analisando essas respostas notamos que os alunos com idades entre 7 e 9 anos preferem ainda as brincadeiras tradicionais, mesmo nesse mundo contemporâneo, cheio de novidades eletrônicas, ainda o contato com o outro através de atividades tradicionais do brincar prevalecem na preferência das crianças. Mas conforme a idade avança, notamos que a incidência de preferência por atividades individuais vai crescendo, no caso acima dos alunos maiores a partir dos 9 e 10 anos. 


\section{SILID IV SIMAR}

Gráfico 5

\section{Como seria a Escola Ideal}

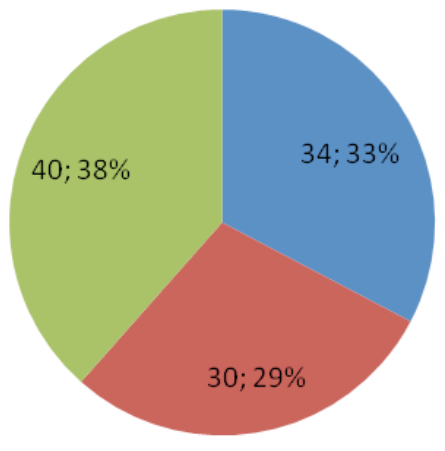

mudesse trazer celular, tablet.

ir a sala de informatica sempre

aprender novas brincadeiras

Por fim ao analisar o ultimo gráfico percebemos que a inquietação grande motivo para iniciar essa pesquisa se revela, ou seja, $40 ; 38 \%$ dos alunos que participaram dessa pesquisa preferem aprender novas Bin cadeiras dentro da escola. A questão para esse gráfico: Como seria a escola ideal, oferecia alternativas, mas a escolhida pela maioria foi a de aprender a se relacionar com os outros.

Para situar o cenário cultural, midiático e educacional que apresenta essa pesquisa e entender a importância da contribuição na formação de professores capazes de educar na nossa sociedade contemporânea com auxílio das tecnologias digitais de informação ou comunicação, partimos da percepção de que na cultura digital ou cibercultura temos a emergência de algo precioso e muito favorável à sala de aula baseada na aprendizagem participativa e colaborativa preconizada e desenvolvida por clássicos educadores. Trata-se da dinâmica cognitiva e comunicacional das gerações que emergem com as potencialidades do computador, do celular e da internet operacionalizados como conectividade, multidirecionalidade, partilha colaboração, interatividade.

A avaliação da incorporação das tecnologias de informação e comunicação na educação formal e escolar, assim como as previsões sobre o futuro dessa área, varia em função do potencial educacional que é atribuído a essas tecnologias e, consequentemente, dos objetivos perseguidos em sua incorporação. Ao serem vistas como conteúdos curriculares e como objeto de ensino aprendizagem, a avaliação é extremamente positiva e as perspectivas de futuro são otimistas. Coll e Moreno (2010, p.87). "Todos os indicadores apontam na direção de uma incorporação crescente das TIC no currículo escolar e não há razão para pensar que o ensino e aprendizagem do manejo e domínio dessas tecnologias possam 
apresentar maiores dificuldades que o ensino aprendizagem de outros conteúdos curriculares."

E ainda Castells (1999 p. 50) uma nova revolução tecnológica, o século XXI está sendo marcado pela universalização das tecnologias digitais e dispositivos móveis conectados em redes, que nos colocam em constante interação com (ciber) espaços sócio-técnicos onde a comunicação ocorre em lugares não fixos registrando fatos e informações no instante em que eles acontecem. Diante disso os jovens são os que mais utilizam esta forma de comunicação, tornando-a uma marca, um hábito dessa geração caracterizada, dentre outros fatores, pela grande imersão nas culturas digitais, constituem-se hoje como alguns dos grandes desafios para a educação, principalmente em sua formação, pois estes jovens são e serão autores e produtores nas redes sociais e por isso precisam ter outra forma de comportamento, na escola, condizente com um modelo de educação que prioriza a reprodução e a transmissão de informação.

Gee (2009) ressalta que os bons videogames incorporam bons princípios de aprendizagem: identidade, interação, customização, desafios, sentidos contextualizados, pensamento sistemático, exploração, revisão dos objetivos, conhecimento atribuído a outros. O autor nos desafia a tornar a aprendizagem, dentro e fora das escolas, mais parecidas com os games, no sentido de que ela use os tipos de princípios de aprendizagem que os jovens veem todos os dias nos bons videogames, quando jogam de um modo reflexivo e estratégico. Para a educação física, a tecnologia dos games também coloca novos desafios e discussão. Ramos (2008) afirma que, dentro desse novo paradigma, o professor tem uma função estratégica quando pensamos na aplicabilidade pedagógica dos jogos eletrônicos e nos reflexos que eles podem ter no desenvolvimento humano. A partir disso aparecem debates, sobre a possibilidade e os obstáculos que possibilitem o diálogo e a incorporação dos jogos virtuais na área da educação física escolar.

\section{Considerações Finais}

Diante das análises das respostas dos alunos sobre gostar ou não de esportes, a maioria respondeu gostar, mas quando nos confrontamos com o que fazem em seu tempo livre, notamos um crescente número de crianças que ficam em casa nos jogos eletrônicos ou assistindo TV. Isso se deve ao fato da maioria dos alunos residirem em prédios, que pouco oferecem na questão do espaço para lazer, isso se comprova nas questões sobre o espaço de lazer em suas moradias. Mas quando observamos os outros gráficos percebemos que as crianças ainda tem grande preferência por atividades que necessitam do espaço e do outro para se divertir. Também quando questionadas sobre o que preferem em sua escola ideal, apesar de preferirem poder trazer seus objetos eletrônicos para o ambiente escolar, a maioria prefere aprender sobre novos esportes e brincadeiras. Mesmo grande parte dessas crianças entende sobre games, gostarem muito de jogar, mas jogar com o outro. 
Esses dados podem nos fazer perceber a importância de olhar com mais atenção para o que quer o aluno. E nos ajuda a entender que ao acrescentarmos 0 ensino das TIC nos planejamentos escolares conquistaremos um direito de acrescentarmos ao aprendizado do aluno algo a mais, ou seja, isso não será motivo de preocupação, mas será um instrumento novo a ser acrescentado à educação. Ao concluir essa pesquisa na escola municipal São Luiz, percebo a necessidade de entendermos mais sobre o universo infantil, suas preocupações, seus anseios e desejos sobre o que querem e esperam do futuro dentro da escola nossos alunos. Percebo também que nós professores da educação básica precisamos mais e mais entender e realizarmos pesquisas de campo para alcançarmos mais sobre o que devemos ou não realizar no nosso cotidiano escolar. O professor não pode viver do "achismo", mas de certezas justificadas e documentadas acerca de seus fazeres do cotidiano escolar, e nesse caso uma das maneiras é a pesquisa.

As TIC hoje fazem parte de uma sociedade cada vez mais conectada em que as informações chegam numa velocidade impressionante, e sim, é extremamente importante que o professor possa pensar sua realidade a partir de práticas relacionadas com essa cultura contemporânea.

Considero que esses debates estão numa realidade não muito distante, que talvez em algumas escolas já enfrentem e outras talvez ainda ensaiem seus primeiros passos. No caso posso afirmar que a Escola Municipal São Luiz está nesse processo, mas que mesmo com todo esse universo das tecnologias ainda vemos na criança a sua preferência por aprender a brincar da forma mais tradicional e divertida.

\section{Referências Bibliográficas}

CASTELLS, Manuel. A sociedade em rede. São Paulo: Paz e Terra, 1999.

A Galáxia Internet: reflexões sobre Internet, negócios e sociedade. Lisboa: Fundação Calouste Gubenkian,

COLL, C. Onrubia, J. e Mauri, T. Tecnologia y praticas pedagógicas: las TIC como instrumentos de mediación de La actividad conjunta de professores y Estudiantes. Anuario de psicologia, 38 (3), 377-400 (2007).

FERNANDES, Florestan. O Folclore em Questão. São Paulo: ED. Martins Fontes, 2003.

Folclore e mudança social na cidade de São Paulo. São Paulo: Ed. Martins Fontes, 2004. 
GEE, P. Bons videogames e boa aprendizagem. Perspectiva, Florianópolis, v. 27, n.1, p.167-78, jan./jun. 2009.

KENSKI, V. M. O impacto da mídia e das novas tecnologias de comunicação na educação física. Motriz: revista de educação física, Rio Claro, v. 1, n. 2, p.129-133, dez. 1995.

PEREIRA, Rita Marise Ribes. Infância, Televisão e Publicidade: uma metodologia de pesquisa em construção. Cadernos de Pesquisa, n 11, 6 julho, 2002.

RAMOS, D. K. A escola frente ao fenômeno dos jogos eletrônicos: aspectos morais e éticos. Revista Novas Tecnologias na Educação, Porto Alegre, v. 6, n. 1, jul. 2008. 